\title{
Development of a rapid DNA screening procedure for the Factor V Leiden mutation
}

\author{
G A Scobie, S T Ho, G Dolan, N A Kalsheker
}

\begin{abstract}
Aim-To develop a rapid, simple and highly specific DNA screening procedure based on the amplification refractory mutation system (ARMS) to detect the Leiden mutation in whole blood.

Methods-ARMS PCR amplification primers with additional mismatches at either -2 or -3 , which greatly improves specificity, were constructed to detect the normal Factor $V$ gene and the Leiden mutation in whole blood samples from patients with abnormal clotting results.

Results-Construction of ARMS primers with either an additional mismatch at -2 or -3 at the $3^{\prime}$ end of the primer could be used to detect the Leiden mutation in $0.5 \mu l$ whole blood in under three hours. Primers destabilised at position -3 could be used at a lower annealing temperature, which gave greater sensitivity and are now routinely used. A control set of primers was included in the same reaction to act as a positive control.

Conclusions-This rapid and specific assay for the factor $V$ Leiden mutation is a useful addition to the investigation of patients with or at risk from thrombovascular disease.

(F Clin Pathol: Mol Pathol 1996;49:M361-M363)
\end{abstract}

Keywords: Leiden mutation, ARMS, whole blood, activated protein $\mathrm{C}$, thromboembolism.

Resistance to activated protein C (APCR) is the most common defect associated with an inherited predisposition to venous thrombosis. ${ }^{1}$ About $95 \%$ of subjects with APC resistance have a mutation in the Factor $\mathrm{V}$ gene which results in a $G$ to $A$ substitution at nucleotide 1691 , referred to as the Leiden mutation. ${ }^{2}$ In Europeans, this mutation has a frequency of $4.4 \%$, but has been found in up to $50 \%$ of selected patients with a personal or family history of thrombosis. ${ }^{3}$ Furthermore, it has been suggested that carriers of this mutation are at a sevenfold increased risk of developing thrombosis and this risk is increased to 30 -fold in female carriers on oral contraceptives. ${ }^{4}$ Activated protein $C$ resistance can be detected by a variety of coagulation based tests, but the Factor V Leiden abnormality can only be detected by direct analysis of the mutation.

We have developed a rapid, simple and highly specific DNA screening procedure based on the amplification refractory mutation system (ARMS) method, ${ }^{5}$ which uses whole blood samples directly in the assay. Normally, the ARMS method relies on the presence of a mismatch between the PCR oligonucleotide primer used and the target sequence such that the mismatch is at the $3^{\prime}$ end (at position -1). In these circumstances the enzyme Taq polymerase functions inefficiently and a PCR product is not generated. This permits a rapid diagnosis directly from two PCRs on each sample.

\section{Methods}

Over 300 patients attending the anticoagulant clinic were typed by amplification of target DNA by PCR and restriction enzyme digest with $\mathrm{MnlI}^{2} ; 100$ of these samples were used in the present study

ARMS PROTOCOL

Standard $50 \mu \mathrm{l}$ PCR reactions $(10 \mathrm{mM}$ Tris- $\mathrm{HCl}, 2.5 \mathrm{mM} \mathrm{MgCl} 2,50 \mathrm{mM} \mathrm{KCl}, \mathrm{pH}$ $8.3,0.2 \mathrm{mM}$ each $\mathrm{dNTP}$ ) were used with 0.5 $1.0 \mu \mathrm{l}$ whole blood without the need to extract the DNA. We also found it necessary to increase the final $\mathrm{MgCl}_{2}$ concentration to 2.5 $\mathrm{mM}$ when using whole blood with sodium citrate anticoagulant. PCR tubes were heated to $95^{\circ} \mathrm{C}$ for five minutes and the temperature maintained. Diluted Taq polymerase $(5 \mu \mathrm{l})$ (3.5 U) was added. Conditions for PCR were as follows: $58^{\circ} \mathrm{C}$ for 30 seconds (annealing), $72^{\circ} \mathrm{C}$ for 30 seconds (extension) and $95^{\circ} \mathrm{C}$ for 30 seconds (denaturing) for 32 cycles on a Biometra thermal cycler for the -3 ARMS primers. The annealing temperature was increased to $60^{\circ} \mathrm{C}$ for the -2 primers only. PCR products were visualised on a $2 \%$ agarose minigel and did not require any further manipulations for a diagnosis to be made. To improve the specificity of the reaction we deliberately introduced additional mismatches at position -2 or -3 with either a pyrimidine to pyrimidine ( $\mathrm{T}$ to $\mathrm{C}$ ) or pyrimidine to purine ( $\mathrm{T}$ to $G)$ substitution in the -2 primers and a pyrimidine to purine ( $C$ to $A$ ) substitution in the -3 primers. This destabilised the ARMS primers further and improved the specificity of detecting the Leiden mutation directly from whole blood samples.

By carrying out two PCR reactions for each sample, one tube with a normal ARMS amplification primer (tube A) and the other with the mutant ARMS primer (tube B), the presence or absence of a PCR product from each tube should permit an accurate diagnosis. An internal pair of control primers was included in the PCR to detect failed amplifications (table 1). 
Table 1 Sequence of PCR primers and concentrations used in the standard $50 \mu l$ PCR reaction. FVL-C, FVL-N, FVL-M are the common, normal and mutant primers for the Factor $V$ Leiden mutation, respectively. -2 and -3 denote extra mismatchs. CF1 and CF2 are the control primers (exon 4 of the cystic fibrosis CFTR gene)

\begin{tabular}{llll}
\hline Primer (5'-3') & Sequence & Concentration $(p m o l)^{\text {Size }(b p)}$ \\
\hline 5' common & FVL-C: GCAGGAACAACACCATGATC & 40 & \\
ARMS & FVLN(-2): ACTTCAAGGACAAAAGTACCTGTATTCCCC & & 231 \\
& FVLM(-2): ACTTCAAGGACAAAAGTACCTGTATTCCCT & 20 & 231 \\
& FVLN(-2): ACTTCAAGGACAAAAGTACCTGTATTCCGC & 20 & 231 \\
& FVLM(-2): ACTTCAAGGACAAAAGTACCTGTATTCCGT & 20 & 231 \\
& FVLN(-3): ACTTCAAGGACAAAAGTACCTGTATTCATC & 20 & 231 \\
Control & FVLM(-3): ACTTCAAGGACAAAAGTACCTGTATTCATT & 20 & 231 \\
& CF1: CAAGTCTTATTTCAAAGTACCAAG & 40 & 479 \\
\hline
\end{tabular}

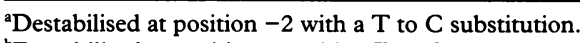

${ }^{b}$ Destabilised at position -2 with a $T$ to $G$ substitution.

'Destabilised at position -3 with a $\mathrm{C}$ to A substitution.

MNII DIGEST

PCRs were set up as for the ARMS PCRs except that the annealing temperature was $61^{\circ} \mathrm{C}$ and the following primers were used: 5'-CA AGTCTTATTTCAAAGTACCAAG and 5-TA AAGCAATAGAGAAATGTCTGTA.

A $14 \mu \mathrm{l}$ aliquot of the PCR product was removed and digested with MnlI for two hours at $37^{\circ} \mathrm{C}$. Digested products were analysed on a $12 \%$ acrylamide gel

\section{Results}

Figure 1 shows the detection pattern obtained with the ARMS procedure on whole blood samples. We have validated this procedure against the conventional use of PCR by digesting 100 whole blood samples with the MnlI restriction enzyme and have found the results to be totally consistent. Diagnosis could be readily achieved using either of the ARMS primers which were destabilised at positions -2 or -3 . However, with the ARMS primers destabilised at position -2 , we found a pyrimidine to pyrimidine substitution ( $T$ to $C$ ) was slightly more destabilising than a pyrimidine to purine ( $T$ to $G$ ) one, in that faint PCR products caused by the mutant ARMS primer annealing to normal sequence were observed very rarely. The ARMS primers with the $T$ to $C$ mismatch gave virtually identical results as the -3 mismatched primers but at a higher temperature $\left(60^{\circ} \mathrm{C}\right)$. Annealing temperatures were slightly different for each pair of primers tested: the -2 primers worked best at $60^{\circ} \mathrm{C}$ whereas the -3 were optimal at $58^{\circ} \mathrm{C}$. Several pairs of internal primers were tried to avoid any spurious bands/primer dimers which could affect signal intensity. We now routinely use the ARMS primers with the additional $\mathrm{C}$ to $\mathrm{A}$ mismatch at position -3 for screening whole blood samples, and incorporate exon 4 primers of the cystic fibrosis gene in the PCRs as a control.

\section{Discussion}

We have shown previously that the Cellmark (Abingdon, UK) ARMS kit can be adapted to detect simultaneously up to five of the most common cystic fibrosis mutations in a single cell. ${ }^{6}$ When developing the ARMS primers for the cystic fibrosis detection kit, ${ }^{7}$ we identified some of the main problems which were also encountered during the development of ARMS primers for the Leiden mutation. To overcome these, we included an extra mismatch to desta-

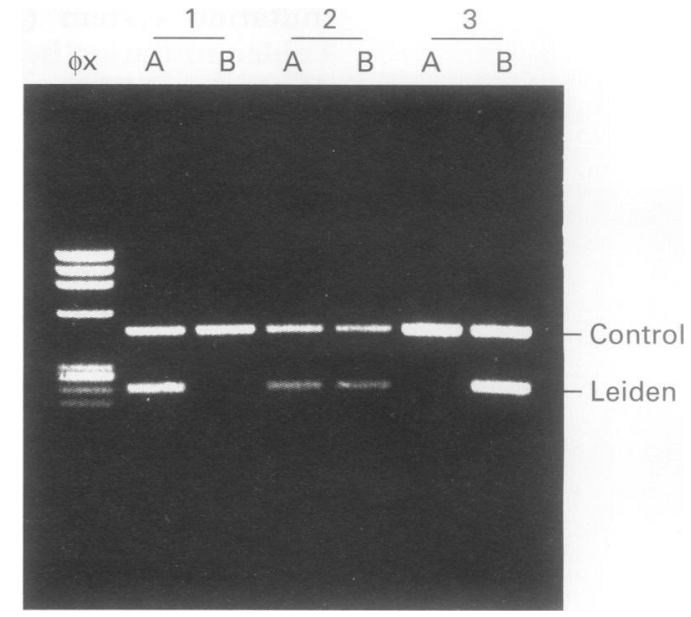

Figure 1 ARMS results on three whole blood samples. Samples 1, 2 and 3 are normal, heterozygous and homozygous for the Leiden mutation, respectively. $A=$ normal and $B=$ mutant $P C R$ reactions. The control band is the internal cystic fibrosis PCR product.

bilise further the annealing of primers to target sequence, and optimised primer concentration and the number of cycles during the ARMS procedure to reduce the likelihood of false positive results. Occasionally, faint bands were observed in the mutant PCR from normal samples, but this did not affect interpretation of the results. Our protocol is similar to that of a recently published procedure, ${ }^{8}$ except that we use whole blood samples for rapid diagnosis and have found that an extra mismatch at position -3 is more sensitive and reliable than either of the primers with a mismatch at position -2 .

The commonly used APTT based coagulation screening test for APCR has some important limitations. It can be unreliable in patients on anticoagulant therapy and in the presence of other coagulation abnormalities, including lupus anticoagulant. It has also been shown recently that in women taking oral contraceptives or who are pregnant, this test may be unreliable as a means of detecting the Factor $\mathrm{V}$ Leiden abnormality. ${ }^{9}{ }^{10}$ Furthermore, this test often yields borderline results which may be difficult to interpret.

We suggest, therefore, that this rapid and specific assay for the Factor V Leiden mutation is a useful addition to the investigation of individuals with or at risk from thrombovascular disease. 
1 Koster T, Rosendaal FR, de Ronde H, Briet E, Vandenbroucke JP, Bertina RM. Venous thrombosis due to a poor anticoagulant response to activated protein $C$. Leiden thrombophilia study. Lancet 1993;342:1503-6.

2 Bertina RM, Koeleman BPC, Koster T, Rosendal FR, Dirven $\mathrm{RI}$ de Ronde $\mathrm{H}$, et al. Mutation in blood coagulation factor $\mathrm{V}$ associated with resistance to activated protein $\mathrm{C}$. Nature 1994;369:64-7.

3 Rees DC, Cox M, Clegg JB. World distribution of factor V Rees DC, Cox M, Clegg JB. World
Leiden. Lancet 1995;346:1133-4.

4 Vandenbroucke JP, Koster T, Briet E, Reitsma PH, Bertina RM, Rosendaal FR. Increased risk of venous thrombosis in oral-contraceptive users who are carriers of factor $\mathrm{V}$ Leiden mutation. Lancet 1994;344:1453-7.

5 Newton CR, Graham A, Heptinstall LE, Powell SJ, Summers C, Kalsheker NA, et al. Analysis of any point mutation in DNA: the amplification refractory mutation system (ARMS). Nucleic Acids Res 1989;17:2503-16.
6 Scobie GA, Woodroffe B, Fishel SB, Kalsheker NA. Identification of the five most common cystic fibrosis mutations in single cells using a rapid and specific differential amplification system. Mol Hum Reprod 1996;2:203-8.

7 Ferrie RM, Schwarz MJ, Robertson NH, Vaudin S, Super M, Malone G, et al. Development, multiplexing, and application of ARMS tests for common mutations in the CFTR gene. Am F Hum Genet 1992;51:251-62.

8 Engel H, Zwang L, Vliet HHDM, Michiels JJ, Stibbe J, Lindemans J. Phenotyping and genotyping of coagulation facdemans J. Phenotyping and genotyping of coag

9 Cumming AM, Tait RC, Fildes S, Yoong A, Keeney S, Hay CR. Development of resistance to activated protein C during pregnancy. Br f Haematol 1995;90:725-7.

10 Oliviero O, Friso S, Manzato F, Guella A, Bernardi F, Lunghi B, et al. Resistance to activated protein $C$ in healthy women taking oral contraceptives. Br f Haematol 1995;91 465-70. 